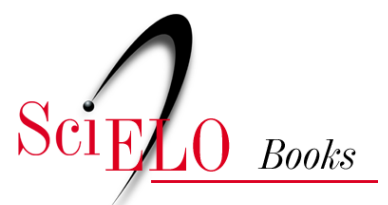

\title{
4. A Bioética, o Início e o Fim da Vida o aborto e a eutanásia
}

\author{
Sergio Rego \\ Marisa Palácios \\ Rodrigo Siqueira-Batista
}

\section{SciELO Books / SciELO Livros / SciELO Libros}

REGO, S., PALÁCIOS, M., and SIQUEIRA-BATISTA, R. A Bioética, o Início e o Fim da Vida o aborto e a eutanásia. In: Bioética para profissionais da saúde [online]. Rio de Janeiro: Editora FIOCRUZ, 2009. Temas em Saúde collection, pp. 95-118. ISBN: 978-85-7541-390-6. https://doi.org/10.7476/9788575413906.0005.

All the contents of this work, except where otherwise noted, is licensed under a Creative Commons Attribution 4.0 International license.

Todo o conteúdo deste trabalho, exceto quando houver ressalva, é publicado sob a licença Creative Commons Atribição 4.0. 


\section{4 a Bióética, 0 Início e 0 Fim da Vida: 0 ABORTO E A EUTANÁSIA}

No capítulo anterior, apresentamos questões relativas à bioética clínica, tendo como foco a tomada de decisão. Entre os problemas debatidos nesse âmbito têm substantiva relevância, desde as origens da bioética, os aspectos atinentes ao início e ao fim da vida.

A tomada de decisão em relação ao princípio e ao termo da existência continua sendo 'polarizada' em torno de duas ideias principais: o princípio da sacralidade da vida (PSV) e o princípio do respeito à autonomia da pessoa (PRA). Em grande medida, as argumentações pró e contra nas questões acerca dos extremos da vida - referentes, por exemplo, ao aborto e à eutanásia - são redutíveis a um desses princípios.

No presente capítulo trilharemos o seguinte caminho: a apresentação dos princípios morais que norteiam o debate - PSV e PRA - e, ato contínuo, a discussão sobre as principais temáticas relacionados à bioética do início e do fim da vida: o aborto e a eutanásia, respectivamente.

\section{PRINCÍPIOS MORAIS}

Os princípios da sacralidade da vida e do respeito à autonomia são elementos essenciais às discussões morais acerca do fim da vida. O PSV pressupõe, em termos absolutos, que a vida consis- 
te em um bem - concessão da divindade ou manifestação de um finalismo intrínseco da natureza -, tendo, assim, um estatuto sagrado, por isso não é mensurável do ponto de vista de todos os 'cálculos' que possam, eventualmente, ser feitos sobre ela, não podendo ser interrompida, nem mesmo por expressa vontade de seu detentor (Siqueira-Batista \& Schramm, 2005). Outra leitura possível acerca da sacralidade ganha força na afirmação de que a vida é sempre digna de ser vivida, ou seja, estar vivo é sempre um bem, independentemente das condições em que a existência se apresente.

A sacralidade da vida é considerada uma das mais contundentes objeções ao aborto e à eutanásia, mormente nas éticas cristãs e na tradição hipocrática. Sem embargo, uma questão se impõe de pronto: se a vida é realmente um bem, quem seria mais competente para julgar essa 'beatitude’? Afirmar de maneira genérica que a vida é algo bom em si mesmo é extremamente perigoso, conforme se constata em muitas das críticas que ganharam corpo ao longo do século XX. Isso se torna claro nas discussões relativas à distanásia - morte lenta, com grande sofrimento - e à obstinação terapêutica (ver adiante, neste capítulo). De fato, a própria assertiva acerca da vida como um bem em si mesmo pode ser questionada - afinal, uma doença grave e incurável, matizada pela dor, pode tornar uma vida insuportável para o titular da existência.

Ademais, como assinalado na posição religiosa anterior, outra questão é o porquê de se considerar sagrada apenas a vida humana. Por que não tratar todas as formas de vida como sagradas? O bioeticista Peter Singer considera discriminatório esse posicionamento, denominando-o de especismo: a exemplo do racismo 
que é a discriminação por raça, o especismo seria a discriminação pela espécie animal. $\mathrm{Na}$ verdade, em termos cristãos, é possível sustentar a primazia da vida humana sobre as demais com base no excerto bíblico: humanos, "feitos à imagem e à semelhança de Deus". Entretanto, para os não cristãos ou não religiosos, ou até mesmo para os panteístas (que consideram Deus e o universo como uma realidade integrada), esse argumento não se sustenta; se não se reconhece que a vida humana tem estatuto "à imagem e à semelhança de Deus", duas perspectivas podem ser adotadas: ou nenhuma vida é plenamente sagrada ou todas as vidas o são.

A acusação de especismo feita por Singer àqueles que defendem a primazia do humano sobre os demais animais não se aplica apenas aos que o fazem por razões religiosas, mas também àqueles que admitem a sacralidade da vida relacionada à solidariedade humana. Com essa compreensão, o sagrado perde o seu conteúdo religioso e passa a significar algo que não se deve infringir ou que não se pode deixar de cumprir.

O princípio do respeito à autonomia da pessoa (PRA) pressupõe que se considerem, definitivamente, as livres escolhas dos sujeitos quando se tratar de questões morais. Reconhece, de fato, que a moralidade implica o estabelecimento de relações entre sujeitos autônomos - ou, ao menos, que um dos implicados seja autônomo (por exemplo, nos debates sobre a eticidade das pesquisas com animais, o outro da relação é um ser que não pode ser considerado autônomo) -, tornando importante que se delimite o conceito de autonomia.

Como já visto no Capítulo 2, a autonomia traz a ideia de autogoverno e autodeterminação. Entre os gregos antigos, dizia 
respeito às formas de governo autárquicas, isto é, as cidadesestado (pólis), organizações sociopolíticas capazes de se autogovernar e de se autogerir. $\mathrm{Na}$ Idade Moderna, o conceito de autonomia passa a se aplicar ao indivíduo, alcançando uma formulação moral sistemática com a Fundamentação da Metafísica dos Costumes de Kant (1988). Nesses termos, podemos definir como autônomo o indivíduo que age livremente de acordo com um plano escolhido por ele mesmo, da mesma forma que um governo independente administra seu território e define suas políticas.

A argumentação pelo respeito à autonomia enfatiza o respeito à liberdade de escolha da pessoa, isto é, sua competência em decidir, autonomamente, aquilo que considera importante para viver sua vida, incluindo nessa vivência os processos de nascer e de morrer, de acordo com os seus valores e interesses legítimos. Desse modo, o PRA pressupõe que cada pessoa tem o direito de dispor de sua vida da maneira que melhor lhe aprouver.

Procuramos ser didáticos nesta apreciação sobre o PSV e o PRA, de modo a permitir a compreensão do núcleo dos argumentos relativos às questões bioéticas concernentes ao início e ao fim da vida. Entretanto, ambos dizem respeito a 'extremos morais', os quais podem se mostrar profundamente imbricados - e, por vezes, até indevidamente misturados e confundidos - no discurso dos envolvidos, conforme mostraremos a seguir.

\section{Bió́tica e 0 InÍCIO DA VIDA: 0 ABORTO}

O aborto é um dos temas mais polêmicos da atualidade e tem fomentado múltiplos debates, mormente nos âmbitos político, médico, jurídico e filosófico. Mas, se a questão é pujante nas 
sociedades ocidentais contemporâneas, tal situação não se caracteriza absolutamente como regra: o aborto foi aceito e praticado por membros de diferentes culturas desde a Antiguidade; passou a ser condenado bem mais recentemente, em 1869, pela Igreja católica (Muraro, 1989). Ademais, de modo geral, a história do repúdio ao aborto vincula-se, em grande parte, aos momentos de declínio da taxa de natalidade, como no período de derrocada do império romano e nos países da Europa Ocidental no início do século XX, após as grandes baixas populacionais sofridas durante a Primeira Guerra Mundial.

O espaço definitivo para a colocação do aborto em pauta, no hemisfério norte, consolidou-se a partir das transformações sociais ocorridas na década de 1960, as quais se relacionaram intimamente às lutas políticas das feministas em prol da liberdade sexual e reprodutiva e ao surgimento da 'pílula anticoncepcional', que tornou possível reduzir enormemente o risco de que um ato sexual se transformasse em uma ação reprodutiva. Por outro lado, nas sociedades latino-americanas, tal movimento ganhou força com um atraso de vinte anos, em decorrência do período autoritário e arbitrário que vigorou na maior parte de nossos países nas décadas de 60 e 70 do último século. Com a redemocratização, nossa população voltou a discutir sobre seus direitos individuais e sociais e a lutar por eles.

O fato de ser considerado um crime no Brasil não impede que o aborto seja amplamente utilizado para impedir a concretização da maternidade, como demonstrou o estudo do The Alan Guttmacher Institute (1994), que estimou a realização de 4.775.000 abortos na América Latina no ano de 1990, 4.620.000 dos quais em condições de ilegalidade (ou seja, em 96,8\% dos 
casos), e, no Brasil, de 1.443.350 abortos ilegais, à razão de 31 por cem gravidezes. Considerar o aborto apenas do ponto de vista legal é fechar os olhos para um problema que insiste em se colocar, diuturnamente, nos serviços de saúde e no âmbito mais amplo da sociedade brasileira. Até porque, como se sabe, as leis mudam com muito menos rapidez do que os costumes e práticas da sociedade. Identificando-se o tamanho do problema, reconhece-se implicitamente o quanto a atividade é praticada, apesar de todas as restrições legais e morais que as mulheres sofrem.

Uma das consequências desse primeiro ponto é a caracterização do 'aborto provocado' como um sério problema de saúde pública no país, na maioria das vezes realizado de forma velada e com resultados catastróficos. São também inúmeros os estudos que detectam o aborto clandestino como importante causa de mortalidade materna no Brasil (Fusco, Andreoni \& Silva, 2008; Diniz et al., 2009).

Nesse caso, uma vez mais, a desigualdade de acesso aos procedimentos médicos se manifesta: as maiores vítimas são as mulheres de baixa renda, as quais, por não poderem pagar um valor que supera em muitas vezes o do salário mínimo de nosso país, acabam recorrendo a práticas extremamente lesivas ao seu organismo - como a automedicação, com medicamentos frequentemente de qualidade e origem duvidosas, e a submissão a técnicas altamente perigosas empregadas por curiosos.

Apesar de haver, hoje, maior liberdade para se interrogar e discutir acerca dos aspectos (bio)éticos do aborto e do seu impacto social e sanitário, muito pouco se tem avançado efetivamente na caracterização mais clara do problema. Destacam-se, entre os fatores que têm contribuído para essa situação: 
- As múltiplas e díspares realidades e ordens discursivas albergadas pelo conceito, na medida em que uma série de motivações e contextos diferentes podem se tornar manifestos na decisão de interromper uma gravidez em curso.

- A dificuldade em manter um debate de alto nível e embasado em argumentação legítima - e não em espúrios 'enredamentos retóricos', os quais têm muito mais o intuito de confundir (com vistas, em última análise, à manipulação dos sujeitos) do que de esclarecer sobre os pontos que estão em jogo neste delicado assunto.

Com efeito, antes de apresentarmos as argumentações pró e contra, torna-se necessário delimitar os conceitos relativos ao aborto.

$\mathrm{O}$ aborto pode ser caracterizado, de modo geral, como a interrupção da gestação antes de ser possível ao concepto manterse vivo no ambiente extrauterino. Em geral, utiliza-se a palavra 'abortamento' para o processo (ou o ato) e 'aborto' para o produto; tal distinção não será aqui considerada, utilizaremos o termo 'aborto' também para expressar o ato.

Há diferentes modos de classificar o aborto. Entretanto, do ponto de vista da bioética, torna-se útil a delimitação proposta por Diniz e Almeida (1998):

1. 'Interrupção voluntária da gravidez', realizada em nome da autonomia reprodutiva da grávida, ou seja, por falta de desejo de levar a gestação a termo (quer esta seja fruto de um estupro ou de uma relação consensual) - como no caso dos pais que optam pela interrupção por impossibilidade de assumir o compromisso da maternidade/paternidade em um dado momento.

2. 'Interrupção terapêutica da gravidez', praticada com o intuito último de salvar a mãe gravemente enferma, para quem a 
continuação do ciclo gravídico acabará desencadeando a morte - como no caso da gestante com diagnóstico de eclampsia.

3. 'Interrupção eugênica da gravidez', executada com base em princípios da eugenia, tais como valores racistas, sexistas, étnicos - o principal exemplo foram as práticas realizadas no Estado nazista, muitas das quais em conformidade com a lei, de aborto imposto às mulheres por questões puramente étnicas.

4. 'Interrupção seletiva da gravidez', motivada pela existência de graves lesões fetais, muitas das quais incompatíveis com a vida - o exemplo mais conhecido é a anencefalia.

É igualmente importante distinguir o aborto segundo a sua gênese, ou seja, se foi espontâneo - quando ocorre por causas da ordem biológica (muitas vezes genéticas ou placentárias) ou provocado, quando oriundo da ação humana, independentemente de sua motivação.

O Código Penal brasileiro foi promulgado em 1940, o que torna evidente, sem a necessidade sequer de uma análise prévia, o seu descompasso com a moral da sociedade brasileira do século XXI. Esse código penal considera o aborto um crime contra a vida (uma subclasse dos delitos contra a pessoa). Entretanto, seu artigo 128 determina que não seja punido o aborto praticado por médico em algumas circunstâncias específicas: I - se não houver outra forma de salvar a vida da gestante; II - se a gravidez for o resultado de estupro e o aborto for precedido por consentimento da gestante ou, quando incapaz, de seu representante legal.

Desse ponto de vista, em qualquer situação que não se enquadre na impossibilidade de "salvar a vida da gestante" de outra maneira e na gravidez que "resulta de estupro", o aborto é con- 
siderado ato criminoso, passível de punição. A não punição está, assim vinculada ao eventual reconhecimento da falta de culpa da mulher, ou seja, ao fato de a gravidez não ter sido resultado de um comportamento 'devasso', o que demonstra o espírito com que a lei foi escrita. Como dissemos, o fato de o Código Penal ser praticamente septuagenário e de boa parte dos debates sobre aborto ter ocorrido na segunda metade do século XX tem suscitado a proposição de modificações na legislação vigente. Duas situações atuais exemplificam tal afirmativa:

O recente embate jurídico em torno do aborto no caso de o feto ser anencéfalo, desencadeado por uma liminar concedida pelo ministro Marco Aurélio de Mello à Confederação Nacional dos Trabalhadores em Saúde em julho de 2004, a qual garantia a sua realização sem a necessidade de aguardar a decisão judicial; a liminar foi cassada por sete votos a quatro em outubro de 2004, ainda que não tenha sido julgado seu mérito.

A recusa, em maio de 2008, pela Comissão de Seguridade Social e Família da Câmara dos Deputados, de um projeto de lei pela descriminalização do aborto (que tramitava há 17 anos na Câmara); o projeto ainda se encontra em análise pela Comissão de Constituição e Justiça e de Cidadania.

A atual polêmica legal em torno do aborto é, em suma, um reflexo de discussões de mesmo teor levadas a cabo na sociedade, as quais se estruturam, muitas vezes, em torno de argumentos éticos e, com frequência ainda maior, em torno de questões religiosas e de gênero.

O debate bioético acerca do aborto situa-se entre dois extremos morais: aqueles baseados no PSV, argumentos contra, aqueles sustentados no PRA, argumentos pró. Para um panorama geral 
sintético, que ofereça uma rápida identificação dos atores sociais envolvidos no debate e suas posições, podemos afirmar que a defesa do PSV, feita, por exemplo, pelo movimento Brasil Sem Aborto, assume a ideia de que a vida é sagrada e, consequentemente, o aborto nunca é bioeticamente defensável. A defesa do PRA, feita pelo movimento feminista em geral - por exemplo, a Rede Feminista -, preconiza que a mulher é livre para decisões sobre a própria vida, incluindo sua sexualidade e reprodução. Desse ponto de vista decorre a compreensão de que aborto é sempre bioeticamente defensável, exceto quando é realizado contra a vontade da mulher. Entre uma e outra posição estão as mulheres do movimento Católicas pelo Direito de Decidir, que reafirmam sua condição de seguidoras de uma doutrina religiosa mas não aceitam certas proibições morais, que entendem não ter fundamento religioso. Para esse movimento o aborto pode ser bioeticamente defensável.

Esse panorama é uma simplificação extrema das discussões morais sobre o aborto. $\mathrm{Na}$ verdade, a maior parte das pessoas assume posições concordes com a 'região de incerteza', na qual as sínteses - muitas vezes racionalmente incoerentes - entre o PSV e o PRA permitem a adoção de pontos de vista nos quais a conciliação entre os extremos é possível.

O núcleo da argumentação contrária ao aborto é o reconhecimento de que a vida é indisponível, em qualquer circunstância, por ser um bem sagrado (PSV). Essa posição é reiteradamente adotada pelos adeptos das éticas religiosas - especialmente, no Brasil, das éticas cristãs -, como expresso na Declaração Quaestio de Abortu, sobre o aborto provocado (Vaticano, 1974), segundo 
o qual a vida humana é o valor primordial que é preciso proteger e promover.

Com efeito, de acordo com o PSV, a vida humana é indisponível, ou seja, nessas situações limite não há espaço para a autonomia, de modo que se tem, de fato, um discurso baseado na heteronomia (Diniz \& Almeida, 1998). Nessa perspectiva, o PSV se desdobra na concepção de que o embrião/feto é, desde a fecundação, uma pessoa em ato ou em potência. Essa posição encerra problemas relacionados à complexidade da ideia de pessoa - conceito muito mais antropológico do que jurídico - e às dificuldades para a delimitação do que é humano - qual é o conceito de homem que subjaz à consideração de algo 'humano'? -, sendo frequente e consistentemente desconstruída pelos autores que defendem o aborto.

O núcleo da argumentação favorável ao reconhecimento do direito ao aborto é a perspectiva do respeito à autonomia reprodutiva (da mulher). Nesse domínio, é paradigmática a analogia elaborada por Judith J. Thomson no artigo "A defense of abortion", de 1971.

Imagine que um dia você acorda, ao amanhecer, e descobre que está em um leito hospitalar, ligado, de algum modo, a um indivíduo que se encontra inconsciente em uma cama ao lado da sua. Você recebe, então, a comunicação de que esse indivíduo é um famoso músico - violinista - com uma enfermidade renal. Ele sobreviverá somente se o seu sistema circulatório for ligado ao de outra pessoa que tenha o mesmo tipo sanguíneo e, no momento, apenas você preenche esses requisitos. Em decorrência disso, você foi sequestrada - por uma sociedade de amantes da música - e, ato contínuo, procedeu-se à ligação. Caso você 
deseje desligá-lo - o que é possível, por se tratar de um hospital bem conceituado -, ele evoluirá inexoravelmente para óbito; ao contrário, se optar por mantê-lo ligado, ao final de (apenas) nove meses, o músico irá se recuperar e você poderá, então, se desligar dele, sem maior risco.

Nesse exemplo, a despeito de o músico ser inocente em relação à conexão dos sistemas circulatórios - assim como seria o embrião - e de ter direito à vida, não há uma estrita obrigação moral em se manter ligado a ele. De fato, por uma motivação qualquer, a decisão por manter a ligação poderia ser tomada, mas, também, por qualquer outra consideração, o violinista poderia ser desligado, sem que este ato seja necessariamente considerado imoral ou criminoso. Com efeito, ainda que o músico/embrião tenha direito à vida, isto "não dá o direito ao uso do corpo de terceiros, mesmo que, sem esse uso, alguém venha a morrer" (Singer, 2002: 194).

A analogia de Thomson é particularmente aplicada à defesa do aborto nos casos de estupro, uma vez que, como o sequestro, o estupro é um ato inequivocamente violento. Mas talvez o argumento de Thomson possa se aplicar a casos em que o acaso ou o desconhecimento, e não uma violência, tenha levado alguém a estar ligado ao violinista. Assim, Peter Singer (2002: 195) propõe: "suponha que você se viu ligado ao violinista, não por ter sido sequestrado pelos amantes da música, mas porque, em visita a um amigo doente, ao tomar o elevador do hospital você, inadvertidamente, apertou o botão errado e foi parar em um setor normalmente visitado apenas por voluntários candidatos a ficarem ligados a pacientes que só assim poderiam sobreviver". Imagine, então, que uma equipe médica que aguardava o próximo 
voluntário confunde você com ele, aplica-lhe uma anestesia e faz a ligação. Nesse caso, Singer questiona se não se pode também usar o mesmo argumento, uma vez que o descuido ou ignorância ou a violência se equivalem em seu caráter involuntário.

A questão, em um ou outro contexto, é a mesma: no final das contas, a decisão, autônoma, deve ser da mulher.

A argumentação aqui apresentada presta-se à defesa da 'bioeticidade' do aborto, núcleo do debate nesta seção. Entretanto, em muitas circunstâncias, as correntes pró-aborto têm um discurso dirigido mais à descriminalização do que à eticidade do procedimento em si. De fato, viver em uma sociedade na qual se pode exercer a liberdade para escolher levar - ou não - uma gravidez a termo é um aspecto essencialmente inscrito no debate atual sobre o respeito à autonomia.

Não se pode esquecer, pela relevância, a perspectiva de gênero na qual está inserida a discussão. Em um mundo marcadamente masculino, a negação do direito ao aborto às mulheres serve também como um instrumento de controle de sua sexualidade. Como disse certa vez Florynce Kennedy, advogada e ativista estadunidense, "se os homens pudessem engravidar, o aborto seria um sacramento".

A questão do aborto talvez seja o campo da bioética no qual as disputas argumentativas são mais acirradas. Esse aspecto - e a constatação de que milhares de mulheres sofrem e morrem, todos os anos, vítimas dos procedimentos utilizados em abortos clandestinos - torna ainda mais imperiosa a discussão, honesta e racional, acerca da sua 'bioeticidade' e dos seus aspectos legais. Sem desconsiderar, todavia, que o debate se dá em um contexto essencialmente dominado por uma visão masculina, segundo a 
qual o controle da sexualidade feminina está intimamente ligado às ações contrárias a qualquer medida de interrupção da gravidez e ao uso de métodos seguros de contracepção, como são as ações protagonizadas pela Igreja católica.

\section{Biótica e 0 Fim da Vida: A EutanÁsia}

A eutanásia é, entre todos os temas relativos à bioética do fim da vida, aquele que mais provoca polêmica. De fato, desde o final do século passado, uma série de eventos tem tornado mais evidente a premência de se discutir a questão, cabendo comentar:

- O progressivo envelhecimento populacional - como observado no Brasil - permite que um maior contingente de pessoas alcance a senectude, tornando-se mais suscetível às moléstias crônicas e degenerativas e, por conseguinte, a um processo de morrer mais 'prolongado' e sujeito a padecimento.

- A aprovação de leis autorizando a eutanásia em vários países do mundo, como a Austrália (de julho de 1996 a março de 1997), a Holanda (abril de 2001), a Suíça e a Bélgica (maio de 2002).

- As indagações relacionadas aos avanços das técnicas de manutenção da vida e prolongamento da sobrevida.

- A ocorrência de várias 'situações clínicas' que levantaram incontornáveis questões sobre a moralidade da eutanásia e do suicídio assistido - casos Karen Ann Quinlan (em 1975-1976, que voltará a ser comentado no Capítulo 5); Diane-Quill (em 1996, uma senhora de 45 anos recebeu o diagnóstico de leucemia e não aceitou ser tratada. Seu médico, dr. Quill, aceitou sua decisão e ajudou-a no seu suicídio); Robert Dent (em 1996 foi a primeira pessoa no mundo a receber a eutanásia com 
autorização judicial); Ramón San Pedro (morto em 1998, teve seu caso de suicídio assistido relatado no filme Mar Adentro); Jack Kevorkian, o "doutor Morte" (médico que nos anos 90 ofereceu, até ser preso, um programa de suicídio assistido); Vincent Humbert (em 2003, esse jovem bombeiro morreu em uma ação de eutanásia ativa) -, somente para mencionar as mais notórias.

Entretanto, ainda que a eutanásia venha merecendo grande atenção da comunidade mundial, o debate está muito longe do desejável na sociedade brasileira. Pelo fato de ser ainda considerada crime no Brasil - como disposto no artigo 121 do Código Penal -, ainda se observa um pacto de silêncio nas unidades de cuidado da saúde, nas quais a decisão por interromper, ou não, a terapêutica acaba por ser tomada às escuras, por profissionais habitualmente sem qualquer preparação para isso e, pior, muitas vezes à revelia dos familiares e do próprio enfermo.

Nesses termos, um dos complicadores - no Brasil e em outros países - é a constatação de que a o termo 'eutanásia' encerra significativa polissemia, o que tem provocado grandes dificuldades nos aspectos relativos ao debate moral sobre o assunto. Com base nessas considerações, apresentaremos o(s) conceito(s) e as classificações da eutanásia e, em seguida, as argumentações contra e pró.

O termo 'eutanásia' foi utilizado, pela primeira vez, pelo historiador romano Suetônio, no século II d.C., para descrever a morte tranquila do imperador Augusto. Essa compreensão da eutanásia como boa morte reaparece na definição de Émile Littré (1908), autor que a define como "boa morte, morte suave e sem sofrimento”. Em termos mais contemporâneos, é entendida 
como a antecipação voluntária do passamento, imbuída de uma finalidade humanitária - sobretudo para a pessoa, mas também para a coletividade à qual pertence o moribundo -, dirigida à suspensão de um sofrimento insuportável. A eutanásia seria, assim, melhor entendida como a abreviação do processo de morrer de um enfermo, por ação ou não ação, com o objetivo último de aliviar um grande e insuportável sofrimento.

Em relação à classificação, atualmente priorizam-se as distinções em termos do ato em si e do consentimento do enfermo. Essas distinções foram sistematizadas por Siqueira-Batista \& Schramm (2005), conforme se segue.

Distinção quanto ao ato:

- Eutanásia ativa - ato deliberado de provocar a morte sem sofrimento do paciente, por fins humanitários (por exemplo, utilizando uma injeção letal).

- Eutanásia passiva - quando a morte ocorre por omissão proposital em se iniciar uma ação médica que garantiria a perpetuação da sobrevida (por exemplo, deixar de iniciar aminas vasoativas no caso de choque não responsivo à reposição volêmica).

- Eutanásia de duplo efeito - nos casos em que a morte é acelerada como consequência de ações médicas não visando ao êxito letal, mas sim ao alívio do sofrimento de um paciente (por exemplo, emprego de morfina para controle da dor, gerando, secundariamente, depressão respiratória e óbito).

Distinção quanto ao consentimento do enfermo:

- Eutanásia voluntária - em resposta à vontade expressa do doente, o que seria um sinônimo de suicídio assistido. 
- Eutanásia involuntária - quando o ato é realizado contra a vontade do enfermo, o que, em linhas gerais, pode ser igualado a homicídio; todavia, a concepção de Helga Kuhse (Kuhse \& Singer, 1998) é algo distinta: a autora caracteriza a eutanásia involuntária como aquela que se pratica em uma pessoa que havia sido capaz de outorgar ou não o consentimento à sua própria morte, mas não o fez, seja por não ter sido solicitada, seja por ter rechaçado a solicitação devido ao desejo de seguir vivendo.

- Eutanásia não voluntária - quando a vida é abreviada sem que se conheça a vontade do paciente.

Do ponto de vista da bioética, podem ser construídos argumentos distintos para as diferentes categorias de eutanásia relativas ao ato em si, havendo aqueles que condenam peremptoriamente a eutanásia ativa, mas "aceitam" a eutanásia passiva - por exemplo, julgando legítimo que um enfermo se negue a passar por medidas terapêuticas extraordinárias, ou seja, recuse a distanásia - ou que, em decorrência de uma determinada modalidade terapêutica, acabe por sobrevir o óbito - no caso, eutanásia de duplo efeito. Todavia, no que se refere ao consentimento do enfermo, há justificativa moral para a eutanásia voluntária e, eventualmente, para a não voluntária, mas não para a involuntária. Abordaremos os argumentos contra e pró a eutanásia a seguir, mas antes apresentaremos, sinteticamente, o que está previsto em alguns dispositivos legais.

De modo análogo ao previsto para o aborto, o Código Penal brasileiro penaliza a eutanásia por entendê-la como homicídio (crime contra a vida); de acordo com o seu artigo 121, é crime matar alguém. Entretanto, seu primeiro parágrafo determina que 
se o agente cometer o crime impelido por motivo de relevante valor social ou moral, ou sob o domínio de violenta emoção, logo em seguida a injusta provocação da vítima, o juiz pode reduzir a pena de um sexto a um terço.

Encontra-se em tramitação no Senado Federal o Projeto de Lei 125/96, de 1995, estabelecendo critérios para a legalização da "morte sem dor". Nesse caso, pessoas com sofrimento físico ou psíquico poderiam solicitar a realização de procedimentos que visem à própria morte, desde que autorizados por uma junta médica e que haja expressa anuência do enfermo (ou de seu familiar, caso este esteja impossibilitado).

No final do século passado, foi criada uma comissão de juristas para elaborar uma proposta de revisão do Código Penal brasileiro. Essa comissão preparou um anteprojeto que não chegou a ser submetido à apreciação legislativa, mas foi discutido em alguns fóruns. No Rio de Janeiro, por exemplo, ocorreu um debate sobre a proposta de eutanásia prevista no anteprojeto, indicando que existe a percepção da sociedade de que uma nova regulamentação sobre a eutanásia é apenas uma questão de tempo. O próprio Conselho Federal de Medicina já elaborou uma resolução sobre a terminalidade da vida (ver adiante), o que também indica a mesma necessidade de se regulamentar o que, de fato, já ocorre.

O mais importante argumento contra a eutanásia diz respeito ao PSV. Nesses termos, considera-se que a vida é sempre digna de ser vivida - independentemente dos sofrimentos aos quais se esteja submetido - e imoral lançar mão de medidas para abreviar o processo de morrer. $\mathrm{Na}$ verdade, para o cristianismo o sofrimento é visto como algo aceitável, e até mesmo benéfico, como 
registrado na "Declaração sobre a eutanásia" (Vaticano, 1980). Nessa declaração, o Vaticano afirma que a dor, sobretudo nos últimos momentos da vida, assume um significado particular no plano salvífico de Deus, sugerindo que o sofrimento poderia ter um aspecto redentor.

Nessa perspectiva, a sacralidade da vida humana e a disposição para o sofrimento tornam muito difícil o desenvolvimento de ponderações em prol da eutanásia. Ainda assim, as dificuldades aqui identificadas em relação ao PSV tornam mais difícil a sua aceitação, para aqueles que não comungam da fé - religiosa ou não - de que a vida, humana, tem um estatuto sagrado.

Outra consideração bastante encontrada na literatura bioética sobre a eutanásia é o argumento de slippery slope - traduzível, em português, como ladeira escorregadia -, com base no qual se pretende justificar que não devem ser feitas "concessões", aparentemente inócuas, em temas controversos, sob pena de se abrir o precedente para atitudes de inequívoco malefício. Nesses termos, oposições alicerçadas no argumento 'escorregadio' incluiriam: a potencial desconfiança - e subsequente desgaste - na relação médico-paciente; a possibilidade de atos não inspirados em fins altruístas, mas motivados por outras razões (por exemplo, questões de heranças, pensões, seguros de vida e outras); a ocorrência de pressão psíquica - por exemplo, o pensamento, pelo enfermo, de que a sua condição é um verdadeiro 'estorvo' para os familiares -, a qual poderia deixar os pacientes, cuja morte se aproxima, sem perspectiva outra que não a 'eutanásia', de fato não desejada e, portanto, de alguma forma imposta por razões circunstanciais; e a erosão definitiva do respeito à vida humana, tomando-se como base o recorrente exemplo do na- 
zismo. Entretanto, nem sempre tal preocupação poderá ser fundamentada, pois o mau uso (ou o abuso) de algo não contraindica, em termos absolutos, o seu uso. Para identificar quais dessas argumentações baseadas na 'ladeira escorregadia' são falácias, basta que demonstremos que a consequência anunciada não é necessária, pode não acontecer.

O PRA, à semelhança do anteriormente descrito nas questões bioéticas acerca do aborto, é o núcleo comum para a defesa da bioeticidade da eutanásia. Nesses termos, se um sujeito autônomo é capaz de tomar inúmeras decisões ao longo da própria existência, torna-se plenamente justificável que ele tenha, igualmente, a possibilidade de decidir sobre o fim de sua vida - especialmente em situações de extremo sofrimento -, quer para mantê-la, quer para extingui-la, quem sabe em prol de uma boa morte, 'eu-tanásia'. No bojo desse debate, a autonomia pressupõe que cada indivíduo tem o direito de dispor de sua vida da maneira que melhor lhe aprouver, optando pela morte no exaurir de suas forças, ou seja, quando sua própria existência se tornar subjetivamente insuportável.

As limitações da autonomia são as mesmas anteriormente comentadas, as quais concorrem para reduzir as possibilidades de aplicação irrestrita deste princípio.

Outros dois elementos são importantes para a argumentação a favor da eutanásia:

1. O princípio da qualidade da vida (PQV), princípio prima facie-ou seja, aplicável somente em determinadas circunstâncias, destituído, portanto, de um valor universal e inatacável -, que afirma também a existência de um valor para a vida, mas aplicável tão-somente se esta for provida de um certo número e grau 
de qualidades, histórica e socioculturalmente construídas, e aceitas pelo titular de uma vida particular (Schramm, 1995). A contraposição ao PSV tem a ver com a possibilidade de atos absurdos, geradores de sofrimentos insuportáveis, apenas para sustentar uma (sobre)vida que pode ser mais um castigo do que uma dádiva.

Uma das questões mais íntimas relacionadas à qualidade de vida está em determinar qual o real significado de uma vida que vale a pena ser vivida, e a quem deve ser dada a prerrogativa de decidir sobre tal significação. $\mathrm{Na}$ esteira da herança do filósofo Immanuel Kant - segundo a qual um ato genuinamente moral deve ser concebido no pleno exercício da liberdade do sujeito ético -, cabe sempre admitir que o principal interessado em viver deve ter a prioridade em decidir sobre sua vida e sua morte. Isso remete, quase que instantaneamente, à questão da autonomia pessoal, considerada o mais importante princípio para legitimar a eutanásia, pelo menos se pensada no contexto das sociedades complexas liberais e democráticas contemporâneas. A qualidade de vida, assim, remete ao PRA.

2. O conceito de compaixão laica (Siqueira-Batista \& Schramm, 2008), entendido não como julgamento do outro - mas tão-somente sua aceitação, o amparo à sua condição de vivente - tem sido identificado como mais um elemento capaz de sustentar a bioeticidade da eutanásia. Assim, ao se reconhecer que a eutanásia pressupõe, de modo inequívoco, a perspectiva de amainar o sofrimento, torna-se significativo adotar uma atitude, em relação ao enfermo inserido no processo de morrer, de respeito a esse seu momento, dispondo-se a atender seu desejo de morrer, sem julgá-lo e sem tomar arbitrariamente decisões tão importantes em seu lugar. 
Levando-se em conta todos os aspectos indicados, torna-se premente ampliar as discussões - acadêmicas e sociais - em torno da eutanásia, procurando equacionar as tensões entre PSV e PRA - igualmente relevantes na bioética do aborto - em um discurso que se institui no bojo de uma sociedade (que se pretende) laica, plural e democrática. Desse ponto de vista, é possível que a compaixão laica - compreendida em suas relações com a ética do cuidado e com a bioética da proteção (SiqueiraBatista \& Schramm, 2009) - permita uma fecunda articulação entre os princípios e argumentos morais acerca do fim da vida, a qual contemple os princípios de sacralidade da vida, qualidade de vida, autonomia, e supere o argumento da ladeira escorregadia. De fato, a vida de um ser humano submetido a excruciante padecimento não deixa de ser sagrada, um valor maior a ser respeitado - colocando-se de lado os dogmatismos cegos e os fundamentalismos - pela decisão autônoma, por parte daquele que sofre, de pôr um fim ao seu curso. Nesse caso, a própria admissão, em meio a um padecimento incurável - e intratável - de que já não vale a pena prosseguir demonstra, em certo sentido, que o doente atribui alto valor à sua própria vida, não desejando profaná-la ao permitir que ela se esvaia em dias e noites de martírios sem fim. Morrer, nesse caso, pode significar também uma clara demonstração de apreço pela própria existência, situando-a em uma dimensão sagrada. E se esse mesmo homem é amparado e - por que não? - protegido, no sentido de tornar fato sua inquebrantável disposição para o ocaso, não se corre o risco de estender, escorregar, indevidamente para situações obscuras e danosas em relação à prática da eutanásia, pois a palavra daquele que sofre, o titular da vida, será sempre a última fronteira. 
O debate bioético sobre o fim da vida, no Brasil, se ampliou, recentemente, com a proposição do conceito de ortotanásia, a "morte no tempo certo". Para os que defendem a adoção deste termo, ortotanásia deve ser compreendida como uma atitude entre a eutanásia e a distanásia, que asseguraria uma morte digna, sem abreviações e sem sofrimentos adicionais, por vezes associada à oferta de cuidados paliativos. A Resolução n. 1.805/2006 do Conselho Federal de Medicina (Brasil, 2006, ver texto completo abaixo), por sua vez, regulamentava a limitação ou suspensão de procedimentos e tratamentos que sustentassem a vida do doente, mas garantindo-lhes os cuidados necessários para aliviar os sintomas que levassem ao sofrimento. Lamentavelmente, essa resolução está com seus efeitos suspensos por decisão liminar do juiz dr. Roberto Luis Luchi Demo, nos autos da Ação Civil Pública n. 2007.34.00.014809-3, da 14 ${ }^{\mathrm{a}}$ Vara Federal, movida pelo Ministério Público Federal.

Resolução CFM n. 1.805/06, sobre a terminalidade da vida Art. $1^{\circ}$ - É permitido ao médico limitar ou suspender procedimentos e tratamentos que prolonguem a vida do doente em fase terminal, de enfermidade grave e incurável, respeitada a vontade da pessoa ou de seu representante legal.

$\int 1^{\circ} \mathrm{O}$ médico tem a obrigação de esclarecer ao doente ou a seu representante legal as modalidades terapêuticas adequadas para cada situação.

$\int 2^{\circ}$ A decisão referida no caput deve ser fundamentada e registrada no prontuário.

$\int 3^{\circ} \mathrm{E}$ assegurado ao doente ou a seu representante legal o direito de solicitar uma segunda opinião médica. 
Art. $2^{\circ}$ - O doente continuará a receber todos os cuidados necessários para aliviar os sintomas que levam ao sofrimento, assegurada a assistência integral, o conforto físico, psíquico, social e espiritual, inclusive assegurando-lhe o direito da alta hospitalar.

Art. $3^{\circ}$ - Esta resolução entra em vigor na data de sua publicação, revogando-se as disposições em contrário. (Brasil, 2006)

Podemos considerar, por fim, que nascer e morrer são pontos extremos na existência humana, reconhecendo, no âmbito da cultura, um grandioso esforço para atribuir-lhes sentido, seja por meio da religião, da filosofia, da ciência ou de outras manifestações do espírito. Essas tentativas incluem ações capazes de trazer significativos problemas éticos - como o aborto e a eutanásia -, os quais deverão ser apreciados pelo profissional da saúde, sujeito que habitualmente precisará tomar (as melhores) decisões sobre a vida e a morte de outrem. No próximo capítulo apresentaremos os diferentes tipos de colegiados usualmente constituídos para o exercício da discussão ética, tratando de suas especificidades e das características que os distinguem entre si. 